\title{
An Interpretation of "Body" as Rhetoric in Yan Lianke's Fiction Creation
}

\author{
Hongxia Lu \\ General Courses Department \\ Hubei Institute of Fine Arts \\ Wuhan, China \\ 23668781@qq.com
}

\begin{abstract}
With the help of Booth's Rhetoric of Fiction theory, we interpret the "body" in order to review the survival paradox in Yan Lianke's novels. In this perspective, "Body" on the one hand survives on the continuous supply of food, and on the other hand exists to supply to life the needed food, only to guarantee the survival and existence of human beings. Additionally, Yan Lianke, regarding "body" itself as one kind of "natural objects", examines in a fantastic way the process of life reproduction and reviews in a fictional way the difficulty of life reproduction and the persistence and adamancies of human beings. As the result, Living-towards-death is the greatest secret of human survival in Yan Lianke's novels.
\end{abstract}

Keywords-Yan Lianke's Fiction; Rhetoric of Fiction; Body as Rhetoric

\section{INTRODUCTION}

Chinese famous writer, Yan Lianke specializes in describing the suffering of the civilian population, and it is also a focus of many researchers, but they rarely to focus on the suffering-takers, the "body" research. As a very special "natural object" in Booth's Rhetoric of Fiction [1], "Body" in Yan Lianke's creation of fiction needs special attention. In literature, body is not only a kind of natural existence, but also an existence of discourse, which means it can be both a subject in presence and an object in disciplines. Yan Lianke's fiction, from novelettes like Year, Month and Day, the Song of Palou, and Memorial Ceremony for Free Falling, to novels like Sunshine in Fleeting Time, Solid as Water, to Live, and Dingzhuang Dream, are full of the image of "body" which has been the most representative "natural object" in his fiction.

\section{II. "BODY" AS RHETORIC}

\section{A. Body and Food}

The hardships of a poor village, firstly comes from the most basic hardship of survival-hunger, which is rooted in the food shortage of body. Food is directly and closely related to the survival of body. "In the context of Chinese language, 'food' has always been endowed with unusual meanings. Any activity, no matter it is cultural, political, military, economic, public, or individual, if traced to its source, can be restored to 'food'. As a cultural symbol, food will finally become the eternal motif and prototype of Chinese culture, just as such words like 'heaven' 'earth' and 'nature' which are closely connected with human survival. ' [2]

The battle between man and food has been always appearing in Yan Lianke's novels. In The Sensibility Prison, the hero Lianke (who is named after the writer's real name) had long been in the state of hunger. So when he found the white steamed bread in the desk, hunger gradually defeated the dignity of life. In the narration of body's sensation of hunger, "I" imagine myself to be a vacant valley_— a pure "natural object", which should be filled, and will disappear otherwise. This metaphor emphasizes that resistance to hanger is body's natural and instinctive response. When hunger becomes the most routine experience in people's experience, human's thought can only be confined to sustaining life. All the behaviors for saving body become reasonable in front of hunger, even if sometimes they are against moral ethics. In The Death Report of the Village, the battle between hunger and body gives rise to the battle between man and ethics. During the year of 1961 when the great famine occurred, a peasant named Liu Binglin determined to save himself when he had to make choices between his child's life and his life. In the beginning, he devoted both the two bows of corn grits soup which were delivered in the collective refectory to his pregnant wife. But in the third day, awakened from a faint due to the dying hunger, he was cruel enough to bite a piece of flesh from his wife's arm. He had realized the importance of keeping alive: "If I was dying, what's the point of having a baby?"[3] For the menial purpose of living, he drank up the light soup belong to his wife. And after her death of hunger, "he even took food for two people from the collective refectory for half a month." [4] His strong desire for life was built on the basis of depriving other's lives. As a result, he was spurned by the whole village because of his total moral bankruptcy. Later, it was mistaken that a car accident happened to him, and all the villagers decided that if there must be someone to die in the accident, it must be him. The extreme torture of hunger to body made people feel that death was better than life, and therefore lost their nature. Being alive became the everlasting expectation of human beings.

The close relationship between food and body has always been Yan Lianke's emphasis. He once exclaimed: "The heart of peasants is given to nothing but food." In Cheng Hao and Cheng Yi's Hometown, the narrator explained their relationship by the words of Cheng Tianqing: "If you have nothing to eat, it is pointless to dress in the 
imperial robe or live in the palace." Just imagine what a big amount of food is needed for a person to live a life in case that he must have three meals a day. Earth cannot be eaten as food; neither can water be drunk as soup. If you have no food to fill your stomach, what's the point of building houses, constructing roads, buying furniture, or building temples? For a handful of dried sweet potato, someone could knee down in front of Tianmin; for a flower bun, Ximei was willing to be dutiful daughter for others and made mourning dresses for them. If you want to be alive, you must take good care of your mouth. Your heart goes with your mouth, so heart always stands on the side of mouth." [5] For contenting the mouth, even in such an ethic society, men can give up the cause of carrying on the family line, and women can cross the bottom line of chastity to have sex with the accountant in the village just "for ten jin of wheat" (Memorial Ceremony for Free Falling). For those village people, hunger is the most basic one among all body sufferings. In Sunlight in Fleeting Time, for the survival of his body, Du Gen can eat his own child for food; for the lives of all the people in the village, twenty-seven disabled children are abandoned in the deep trench as baits to attract ravens. For survival, people even reduce their food to animals. Sima Xiaoxiao eats the leaves of sweet potato which are stained with soil and sand directly, and fills the wheat bran in her mouth together with some unboiled water, "using the tongue to make the bran to paste".

The extreme hunger deprives people of any pursuit of reason. Being alive and keeping alive is the only dream of life. When the narrator presents every scene where people are tortured by hunger to us readers, we can't help "feeling sympathy for their misfortune", but not "feeling angry about their unwillingness to fight". Spiritual sores are the hardships of people who have no worry about the shortage of food. They never taste and can never understand the human's bottom suffering-hunger. Hunger interrupts people's thought, making it always stay in the circle of searching for food. And their eyesight is also shortened, only directing down to the earth. So it is understandable that Big Daddy (Year, Month, and Day), when he accompanies the maize to grow, describes the difference between the growth of crops and that of trees like this: because it is crop, it has to grow leaf by leaf; while those are trees, they can grow leaves by leaves. Such thought can be called "primitive thought" which needs no thinking process and any knowledge. Being alive is just for being alive. Besides, Big Daddy's "primitive thought" includes his distain to "knowledge". He thinks it nonsense that some scholars say the earth is rotating and that when the earth completes rotating a circle, a day draws to the end. In his view, if the earth rotates, "why can't it turn us down when we are sleeping in the bed? Why isn't water in the vat pored over and water in the well flowing out? Why do people always walking with the head towards the sky? ...... They say it is because the earth draws us with force that we don't fall off the bed when we are asleep. But think about it! If we are drawn by the earth, why are we able to lift our feet when we are walking?" [6]. After long time indulgence in the hardships of life, man's sight has been totally veiled by instinct. They keep their eyes fixed in the closed world of food, which makes them fail to strike any conversation with the outside world. To make it worse, a tendency of "antiintelligence" may occur. By adopting some narrative strategies, the narrator makes such numbness understandable to the readers. Before solving the living problem, spiritual matters can only be secondary in their concerns. Just as what Yan Lianke says, "poetry does not exist in a real countryside"; "people always criticize peasants' numbness. Numbness certainly should be criticized, but it should be realized that peasants can use such numbness as powerful weapons to fight against the unfairness that the society gives them. People keep on criticizing numbness, because they don't understand peasants at all, and their knowledge about peasants is unclear and not comprehensive" [7]. In fact, numbness grants peasants with a spirit of "ignorance fears nothing", which is a necessary weapon for them to defeat fate.

When other people leave the village for the outside world begging for food, Big Daddy, with his "primitive thinking", grasps the idea that the secret of the village life lies in "seed", and in "food". Only when "food" is protected can the whole lives of the village are saved. The existence of body needs the nurturing of food. Therefore, protecting food is the root of sustaining life. Big Daddy holds the last hope of survival of the village by sacrificing his body to raise grain. From an indiscriminate eater to a food protector, he demonstrates not only the importance of body, but also the respect of life generation in the national culture. When life is reduced to the degree that only "body" is the "dasein", people have no choice but to protect body. As a martyr of saving life and the nation, Big Daddy has presented very strong awareness of "dasein". Although the seven maize fruits fail to prevent the village from destruction, they bring about hope of reproduction. When the famine year comes again, the seven fruits succeed in retaining seven strong young men in the village. They keep raising the seeds and make life continuing. The narrator restores life to its original state, adopting body as rhetoric, and food, the necessity of body, as the rhetoric of rhetoric. Big Daddy's protection of food is a representation of the most original faith of life, and such faith is not the struggle of an individual. Big Daddy is not Santiago in the novel The Old Man and the Sea, who fights with the shark with the only purpose of proving himself. He closely connects the life of an individual with the lives of a group, which high lightens the collectivism in Chinese culture.

In the texts, the narrators present strong consciousness of conversation. They explore the deep historical reasons for the nation's numbness by demonstrating the difficulty of "survival" itself. In this sense, the enlightenment spirit of the May Fourth period is negated. Body should be regarded as "dasein". However, the appeal to national intellectuality in that period was divorced from the necessity of "dasein", so it can only be a "monologue" in history. The novels have stopped continuing the so-called "reason" "enlightenment", but directly restore to body, and give pure presentation of the nature of life. Yan Lianke makes "body" the centre of daily life, and the undertaker of all the social symbols and 
meanings. In Year, Month, and Day, body has become a ritual of life. "Dasein" is highly respected through sacrificing Big Daddy's body to food. After eliminating all connections, such as "intellectuality", with culture and symbols, the co-presence of body and life is high lightened. The state of being alive itself becomes the meaning of being alive (in another sense, being alive is meaningless). Humans, abandoned in the earth by God, always prove the meaning of their lives through some continuous meaningless struggles, just like Sisyphus who has to fight in the battle between his life and the giant stone year after year.

\section{B. Body and Reproduction}

The eternal existence of the body attributes to the food intake as well as and more to the reproductive ability, which has been the instinct of the continuous existence of an ethnic group and has been the only effective weapon to fight with the finite life of one human against the infinite time of the universe. It not only ensures the continuation of life, but also guarantees the "dasein" of ethnic groups.

In Sunshine in Fleeting Time, death follows as the shadow of Three-surname Village, where people are refused by the outside world either in migration or marriage, which together stimulates their will to survive. As a community, they are not willing to perish. Cripple $\mathrm{Du}$, who has been in the outside world for thirty years, now the village head, said "if the Three-surname Village wants to have a flourishing population, the women here must quickly give birth to babies, just like pig to piglets, so that the new-born population exceed the random-death one"[8]. When the female becomes a tool of reproduction, the disaster of the female body is coming. They have to accept the sexual life even just after their confinement in childbirth because they are assumed to shoulder the responsibility of making the Three-surname Village stand in the world. One Character, Sima Ye, who can no longer bear such reproductive disaster, targeted the village head for the proposal of resisting death by birth:

The female gets pregnant for reproduction and therefore the population expands continuously, which leads to the expansion in the demand for materials for living. The male, far from meeting this demand by their physical labor, can only make a living by selling their skin. The narrator describes the process of "selling the skin" through the eyes of Sima Lan in her childhood:

He found that the doctor peeling a human's skin was just like his father peeling a rabbit's skin. The doctor took a rubber glove, and pulled a long willow-shape skin with his left hand thumb and index finger from his father's leg. The knife under the skin was pulled cautiously from outside to inside, step by step, not any damage to the skin. The doctor, compared with his father, was much more skilled at peeling skin. When his father peeled a rabbit's skin, he often made no clear line between the meat and skin. The doctor, however, could peel a piece of silk-like skin with no bloodstain but red color. Father's leg, not bleeding like a stream after the peeling, would only turn red slowly like just one falling on the ground with skin broken. Later the leaching blood appeared on the surface like the sweat on a wall of a new brick house after one night. Then, while the nurse cleared the leaching blood with white gauze, and the doctor would quickly peel twice under the skin before the nurse did the clearing again. [9]

In order to survive, the female bears continuously injures in their body for breeding while the male sells their skin as a product when they cannot create wealth for living by physical labor. It has been a way of living rather than a temporal method for an emergency. Just as Sima Xiaoxiao said, "selling the skin" involved all the happiness of a man, which could make so much wealth that only one sale could provide a family with the pocket money for two years or the expense for a man to marry a wife. The narrator put the story into the despair of life: "body" has been the only support of humans and has to be sacrificed for survival and reproduction. While, unfortunately, one's body is limited. No matter how many babies you borne, how much skin you sell, it has to go through birth and death, illness and oldness, and the ultimate demise. It is due to the fear of demise; life becomes particularly precious and important.

Considering the course of life, production may be transient, but the reproduction process is lengthy. In The Song of Palou, Mrs. You, as a woman and a wife, not only suffered the reproductive disaster, but also experienced the rearing pain.Reproduction of life is unpredictable, reproduction by body itself is a kind of suffering and reproduction finally brings a family much more misfortune. Mrs. You's life has been rewritten and her happiness in opera performance has been replaced by the birth of her four idiot children. When doctor claimed them as incurable, her husband committed suicide by drowning himself in a river. Mrs. You has to do the farming as a man and rear the children as a mother, for her, to die is enjoying life while to live is suffering disasters. However, she did not give up. She did much more to let her children survive, even to protect their dignity. The Three-surname Village got the name, Village of You's Four Idiots, which made the villagers angry and therefore they prevented Mrs. You to find husbands for her two daughters. Mrs. You got furious, and she dear to fight against those villagers as well as the so called destiny. Compared with the male, the female is much stronger when facing disasters in life.

In the patriarchal structure of division of labor, male is regarded as a privileged gender and they should engage in more advanced social activities rather to create a culture or a symbol of durability. While female is an affiliated gender to male, just existing for the natural function-reproduction. Therefore, in the society, male is associated with ration, reason, reliability and the space outside the family, while female is connected with maternity, affection, lust and the room within the family. When life balance is broken, the husband, facing the impossible mission in life, chose with ration to give up both body and life. So here, the maternity became the Savoir and the instinct of maternity told her that being alive mean everything and living in heath is most successful. When the second son-in-law said he had dreamed that bones of relatives can cure leprosy, she immediately dug her husband's grave for his bones. Seeing the recovery of the second daughter, she was quite excited, 
but just for a moment. "The excitement on her face gradually faded, replaced by a layer of hardened gray."[10] She decided to die for her children's heath. She told her fourth child to put exactly well her coffin so that her bones would not rot even for decades. The body has to sacrifice for the reproduction, and now has to be the medicine of their healthy life. The narrator put the body as the tie of life in an extreme way, making life go on through death by connecting lives together with body after their separation. Being-towards-death makes body heroic. Mrs. You became the sacrifice for life continuation, and started her opera just like thirty years ago:

The girl herself raises her head now
Because she gets her ball-how
The maid yelled yesterday
Turns the madam today
Can now yell
- hey, Xiaolian, foot massage!

She, at the cost of life, swept of the shame of giving birth to four idiot children, won back her dignity and guaranteed her children's happiness. This, however, far from the end, is only the beginning of life cycle. Her four recovered children cried with great grief at her funeral, while she as a die person spoke out the cruelty of life, "leprosy is genetic. So now you all know how to cure your children in the future?" [11]

The narrator examines in a fantastic way, from the birth to the death of leprosy, the process of life reproduction. The disaster without warning, the recipe in dream, the body of relatives, and the words by dead serve to review the difficulty of life reproduction, which at the same time conveys the persistence and adamancy of human beings. As long as human beings are in reproduction, the sacrifice of body will never stop. Living-towards-death is the greatest secret of human survival.

\section{SUMMARY}

Body is regarded as a kind of rhetoric, whose existence form in literature is divided into two types, one is the visible body, namely its narrow sense, referring to the body discourse appears in the texts and the other one is the invisible body, referring to the body projected by the narrator's narration, language, rhetoric device and etc. and the speech, action, behavior and etc. of the characters in narration. Just like the "coat" of "Beatles", "body" itself is one kind of "natural objects", and in literature, its form of "presence", combined with the structure and context of texts, embodies its essence as a rhetoric device after the process of disguise and fabrication.

At the same time, body as a natural object, must subject to the process of birth, decay, death and etc. once this process applied in literature, it becomes instantly the cultural beliefs, symbols and the "meaningful" event in the practical world. Therefore, from the aspect of individuals, body is in an extreme environment under experience, through which, we find out that our body and self-emergent is integrated, namely, we ourselves is the body when we own our body. Yan Lianke's creation of fiction reveals, by regarding "body" as a rhetoric device, the paradox of human existence.

\section{REFERENCES}

[1] Wayne C. Booth: The rhetoric of rhetoric: the quest for effective communication, Malden, MA: Blackwell Pub., 2004.

[2] Hu Zhijun, Food: The dual allegory of history and human nature, Literary Criticism, vol.2, 2002

[3] Yan Lianke, The death report of the village, Beijing: People's Daily Publishing Corporation, pp. 85, 2007.

[4] Yan Lianke, Hello, Jinlian, Cheng Hao and Cheng Yis hometown, Beijing: People's Daily Publishing Corporation, pp. 35, 2007.

[5] Yan Lianke, The death report of the village, Year, Month, and Day, Beijing: People's Daily Publishing Corporation, pp. 303, 2007.

[6] Yan Lianke and Liang Hong, Red chopsticks of the witch, Shenyang: Chunfeng Art and Literature Press, pp. 162, 2002.

[7] Yan Lianke, The death report of the village, Year, Month, and Day, Beijing: People's Daily Publishing Corporation, pp. 324, 2007.

[8] Yan Lianke, Sunshine in the fleeting time, Beijing: People's Daily Publishing Corporation, pp. 415, 2007.

[9] Yan Lianke, Sunshine in the fleeting time, Beijing: People's Daily Publishing Corporation, pp. 429, 2007.

[10] Yan Lianke, The death report of the village, The Song of Palou, Beijing: People's Daily Publishing Corporation, pp. 342, 2007.

[11] Yan Lianke, The death report of the village, The Song of Palou, Beijing: People's Daily Publishing Corporation, pp. 383, 2007. 